\title{
LA SOCIABILIDAD REFLEJADA A TRAVÉS DE LOS DISCURSOS DE LA ACADEMIA DE LOS NOCTURNOS (VALENCIA, 1591-1594)*
}

\author{
Mechthild AlberT \\ Universität Bonn \\ malbert@uni-bonn.de
}

$\square$ 1 concepto de sociabilidad acuñado por Maurice Agulhon se ha afirmado, a lo largo de medio siglo, como un instrumento metodológico particularmente productivo en el ámbito de las Humanidades, entre ellas los estudios culturales y literarios (Albert, 2018). También los especialistas del Siglo de Oro se han valido con gran provecho de este concepto clave (Albert, 2013a y b) al estudiar, por ejemplo, las fiestas cortesanas (Lobato y García García, 2003) o el ocio urbano de la era barroca, marcado por el ascenso de una «nueva nobleza» (Romero-Díaz, 2002). Evidentemente, la recepción hispánica del Cortegiano de Baldassar Castiglione (1528, traducido al español por Boscán en 1534), del Galateo de Giovanni Della Casa (1558, traducción modificada por Lucas Gracián Dantisco en 1593) y de otros tratados de urbanidad de origen italiano, hasta el Discreto (1646) de Baltasar Gracián, proporcionaban el soporte teórico-conceptual a un buen número de prácticas culturales como el sarao y el estrado, los convites y las academias.

Estas últimas cumplían un importante papel sociocultural en este momento histórico, pues «eran, en cierto sentido, las sedes físicas, el espacio social y [...] hasta fenomenológico de lo que Bourdieu entiende por campo literario» (Gutiérrez, 2005: 55; Bourdieu, 1992), constituyendo el eje decisivo entre sujeto literario y campo literario en el momento de la emergencia de estos fenómenos y estructuras. En cuanto a los círculos entre públicos y privados, las academias cultivaban la distinción, otorgaban capital simbólico y contribuían a la distribución

* El presente artículo se sitúa en la estela del proyecto «Los saberes del ocioso-Muße, Gesellggkeit und Wissen im Siglo de Oro» financiado por la DFG (Deutsche Forschungsgemeinschaft / Comunidad Alemana de Investigación) de 2012 a 2015. Asimismo se inscribe en el grupo de investigación hispano-alemán «Saberes humanísticos y formas de vida / Humanistenwissen und Lebenspraxis».

Edad de Oro, XXXIX (2020), pp. 145-157, ISSN: 0212-0429 - ISSNe: 2605-3314

DOI: https://doi.org/10.15366/edadoro2020.39.007 
de oportunidades de poder (Cruz, 1995 y 1998). Con vistas al campo literario en formación, al emergente tipo del escritor profesional (Strosetzki, 1997) le proporcionaban redes y mecenazgos. En su estudio sobre el nacimiento del escritor, Alain Viala (1985) identifica varios motivos por los cuales, en el siglo XVII, «los literatos franceses se adhirieron al movimiento académico» (Gutiérrez, 2005: 45), mencionando en primer lugar las posibilidades de sociabilidad que ofrecían las academias, sobre todo, para neófitos o recién llegados. En segundo lugar eran determinantes las oportunidades de formación e información que proporcionaban, así como el apoyo mutuo como, por ejemplo, mediante elogios cruzados. A través de ellas se aspiraba tanto al reconocimiento y la consagración individuales como a la legitimación colectiva (Gutiérrez, 2005: 45-46), sin olvidar el motivo puramente material y económico (Cruz, 1995). Aparte de este contexto causal, las academias, al experimentar con diversos géneros literarios y al negociar las normas estéticas dominantes, contribuían asimismo a formar el gusto de las élites urbanas y a abrir mercados. Finalmente, en cuanto forma de sociabilidad semipública, las academias formaban parte de la cultura festiva de la villa y corte y de ilustres capitales de provincia (Rodríguez Sánchez de León, 1989).

En consideración del importante papel sociocultural que las academias cumplieron en el momento histórico del Siglo de Oro, no es de extrañar que esta institución, con sus finalidades y rituales específicos, haya tenido una importante proyección literaria. Llegaron a formar un elemento temático y estructural de determinados géneros literarios como son las misceláneas, la novela pastoril y las colecciones de novela, en particular la novela académica, subgénero definido y descrito en 1963 por Willard F. King, cuyo ejemplo paradigmático es la Casa del placer honesto (1620), de Alonso Jerónimo de Salas Barbadillo. De esta manera se configuraba una literatura de carácter metaacadémico, demostrando la existencia de un «campo literario (auto)consciente y activo» (Gutiérrez, 2005: 47).

Un testimonio de esta actividad autorreflexiva son los discursos dedicados a determinados aspectos de la sociabilidad y presentados en el marco de la Academia de los Nocturnos, institución cuyo origen y finalidad consistía en la sociabilidad culta y que celebraba sus reuniones semanales entre 1591 y 1594 . Fuertemente influenciada por el modelo italiano, esta academia valenciana, una de las primeras en la península ibérica, complementaba los ejercicios poéticos con conferencias de índole humanística. Algunas de ellas, consagradas a los siguientes temas, constituyen una reflexión sobre la sociabilidad desde dentro de la sociabilidad académica, formando por ello la base del siguiente análisis:

Sombra (i.e. Gaspar Aguilar): «Discurso de la excelencia de los combites», 1. ${ }^{\circ}$ Día, 4.10.1591 (Canet, Rodríguez y Sirera, 1988: 65-71).

Miedo (i.e. Francisco Tárrega): «Discurso o recopilación de las necedades más ordinarias en que solemos caer hablando, introducidas en nuestro lenguaje por el 
uso inadvertido y común de los hombres», 29. ํía, 15.4.1592 (Canet, Rodríguez y Sirera, 1990: 369-389).

Sueño (i.e. Hernando Pretel): «Discurso contra la demasiada cirimonia común», 71. ${ }^{\circ}$ Día, 15.12.1593 (Canet, Rodríguez y Sirera, 2000: 212-219).

Resulta altamente significativo que la «lición» inaugural de la primera reunión de la Academia de los Nocturnos trate de la «excelencia de los combites», tema encargado por el presidente de la recientemente fundada institución a Gaspar Aguilar, precisamente el más desfavorecido de los académicos en términos socioeconómicos, puesto que era hijo de un pasamentero (Canet, Rodríguez y Sirera, 1988: 13), lo que «le obliga en el exordio a justificarse y exculparse» (Canet Vallés, 1993: 108). A partir de esta situación nada cómoda, que correspondía a determinado planteamiento irónico habitual entre los Nocturnos, «Sombra», por lo demás «único poeta profesional» (Canet Vallés, 1993: 108) en la Academia, empieza por distinguir el quién, a quién y cómo de los convites, según las normas tradicionales del decorum. Partiendo de la etimología del término «con-vivium» explicada por Cicerón en De senectute (Canet, Rodríguez y Sirera, 1988: 66), el ponente considera el banquete como «camaleón que se vuelve del color de quien le haze» (1988: 68) — según si se es rico o avaro, vicioso o templado—. Después de rendir tributo al planteamiento humanístico-erudito de la Academia al mencionar los ejemplos de Calígula, Nerón y Eliogábalo, Gaspar Aguilar se centra en el convite «liberal y franco» ${ }^{1}$ : «mi intención no es sino tratar de combites donde se ganan voluntades y no se pierden haziendas» (Canet, Rodríguez y Sirera, 1988: 69). Con ello se refiere, de manera implícita, a los debates contemporáneos sobre la pertinencia de los convites y sus eventuales daños económicos, sociales y de salud - un discurso crítico que va desde el Banquete de nobles caballeros de Luis Lobera de Ávila (Augsburgo, 1530) hasta los cuadros costumbristas del moralista Juan de Zabaleta, de mediados del siglo XVII (Albert, 2012) _ . En cuanto a sus fuentes contemporáneas, Gaspar Aguilar no menciona al médico de Carlos V, pero sí al humanista y académico napolitano Giovanni Pontano y su tratado De conviventia (Canet, Rodríguez y Sirera, 1988: 69, nota $10 ; 70$, nota 14). Según la estrategia argumentativa propia de los discursos de los Nocturnos (Canet Vallés, 1993: 107), las referencias a las autoridades de la antigüedad clásica gentílica, como el Simposio de Platón, son seguidas por citas bíblicas. En el presente caso, el ponente se refiere a tres conversiones que Jesucristo operó en el marco de sendos convites, a saber las bodas de

1 A este respecto resultan interesantes los diferentes tipos de sociabilidad y entretenimiento que distingue Aguilar: «[...] el que haze un juego de cañas merece el nombre de galán; el que ordena juegos de dados o naipes de cudicioso; el que junta corrillos y conversaciones de maldiciente; y el que se acuchilla de contino de temerario. Solamente el que haze combites merece nombre de liberal y franco» (Canet, Rodríguez y Sirera, 1988: 66). 
Caná, el banquete del fariseo donde convierte a María Magdalena y la última cena, «donde convirtió el pan en su santíssimo cuerpo» (Canet, Rodríguez y Sirera, 1988: 71). Distingue, como corresponde a la inspiración tridentina de los Nocturnos, los manjares del cuerpo de los del alma, pero sin concluir con la misa, eucaristía y comunión, sino con un giro autorreferencial a «nuestra Academia» donde

la perfición del combite yguala la calidad de los combidados, los quales podrán comer por principio sabrosas frutas de poesía, y por medio provechosos manjares de historia y moralidad, pero con condición que no esperen postre ni fin, porque los combites de las almas no le tienen (Canet, Rodríguez y Sirera, 1988: 71).

La metáfora de la Academia como «banquete de Minerva» que brinda a sus socios «regalados platos» en «cenas nocturnas» (Canet, Rodríguez y Sirera, 1990: 374) también aparece en el discurso que «Miedo» pronuncia en la sesión 29, el 15 de abril de 1592, a propósito de «las necedades más ordinarias en que solemos caer hablando, introducidas en nuestro lenguaje por el uso inadvertido y común de los hombres» (1990: 369-389). El ponente no es sino el canónigo y conciliario de la Academia, Francisco Tárrega, «representante del brazo eclesiástico» responsable de la impronta contrarreformista de la Academia y al mismo tiempo «considerado como la persona de más importancia literaria dentro de la Academia» (Canet Vallés, 1993: 104). En su exposición, Tárrega parte de la relevancia antropológica de la lengua y afirma que:

[en] el hablar ordenado se destinguen los hombres de las bestias, y [...] que no faltó quien dixesse de los que hablan neciamente que eran brutos racionales, de manera que la lengua es la muestra del paño que en el entendimiento se labra, y el toque del metal que rinde la mina del pecho (Canet, Rodríguez y Sirera, 1990: 370).

La singularidad del presente discurso consiste en su carácter empírico, pues, al contrario de las demás lecciones, basadas en su mayoría en lecturas enciclopédicas, Tárrega presenta los resultados de un trabajo práctico, por ser «la materia que trato tan estendida como poco estudiada» (Canet, Rodríguez y Sirera, 1990: 374). Una vez que la semana anterior el señor presidente de la Academia le había encargado este tema y «[s]in hallar autor que lo tratase», emprende una investigación de campo «entre [sus] amigos», «and[ando] a caça de esta materia» (1990: 374). A lo largo de sus pesquisas lee, escucha y anota «un millón» (1990: 370) de «disparates» (1990: 374), así como «impertinencias» ratificadas por el «común abuso» (1990: 373) que va sistematizando a través de una tipología «divid[ida] en cuatro partes como géneros suppremos, de los quales 
se deriven las categorías de las faltas comunes que he podido hallar entre mis amigos» (1990: 374). El primer grupo lo forman las «necedades imposibles, las quales en tanto repugnan la razón en quanto no se avienen con la naturaleza o con la posibilidad de las actiones» (1990: 374). Entre los ejemplos mencionados figuran tanto citas literarias que provee de comentarios burlones - por ejemplo «“iÁbreme, bujarrón, ábreme puto, que te quemaré el alma, luterano!”, que no hay inquisidor que tal haga» (1990: 375) - como locuciones hiperbólicas del habla cotidiana, como «los que de muy acosados de sed "se beven un cántaro" y de muy ambrientos "se comen una olla entera"» (1990: 375-376). La segunda categoría corresponde a las «comparaciones mal forjadas e impertinentes que causan a veces risa, y la causarían mayor a no haver hecho d'ellas hábito el abuso común en nuestro ordinario trato» (1990: 378). En este apartado figuran tanto comparaciones impropias tales como «hermosa como una pintura», «reyr como un descosido» o «tañer, cantar o justar como un diablo» (1990: 378), como redundancias específicas de la homilética, pues de ellas pecan en particular «los predicadores que suelen roçar a cada lançe este término: "Dixo el S(pírit)u S(ant)o, y dixo bien", [...] "veen las cosas por sus ojos", "oyen las nuevas por sus oýdos", "tocan con estas manos" y "dizen bellezas de esta boca"» (1990: 381-382). La tercera clase de «faltas comunes [...] afectadas» se refiere más concretamente al incipiente cultismo, pues en esta sección, Tárrega censura las «monstruosidades compuestas de ignorancia y sciencia, como son las palabras latinas españoladas, o por otro nombre españolas enxertas en latín o en otra lengua estrangera» (1990: 383). Como muestras de un «millón de vocablos que podría castigar la lengua castellana como espías de la latina», el canónigo desaprueba no solo el lenguaje poético — «clarífica aurora», «rutilante Phebo», «ebúrneos dientes»sino también modismos corrientes, sosteniendo: «No puedo çufrir que se diga "en el interín" por entretanto; "carta misiva" por la que se imbía de un amigo a otro; "razón bien adjectivada" por bien compuesta; "queso metusalemo" por viejo; "vade mecum" por bolsa para llevar cartapacios» (1990: 383). Y antes de relatar una serie de anécdotas ilustrando el mismo fenómeno, Tárrega declara sin dejar lugar a dudas:

Y a este propósito vienen los cuento que por aý corren fortuna entre lenguas de sacristanes, dignos de que por ellos el culto lenguaje español atendiesse a desterrar de sus heredamientos estos enemigos solapados, que con trages mentirosos de su nación les va ganando tierra y sembrando sizaña en los fértiles campos de su elocuencia (Canet, Rodríguez y Sirera, 1990: 383).

El «catálogo» (1990: 374) de lo que Tárrega considera como «necedades» finaliza con las empresas mal compuestas, en las que cuerpo y alma, imagen y texto no concuerdan y respecto a las cuales el canónigo propone «un riguroso 
auto de varias cosas que han servido de martyrio a mil ojos y entendimientos» (1990: 385), así como lo harán, unos dos lustros más tarde, el cura y el barbero en su escrutinio y quema de los libros de caballerías que han trastornado el entendimiento de Alonso Quijano ${ }^{2}$. El presente discurso es considerado por Josep Lluís Canet como

una buena muestra sobre el estudio del lenguaje, el conceptismo, la afectación, la poesía del momento, etc., en el que se demuestra bien a la cara la postura de Tárrega y de la mayoría de los académicos en contra de las afectación y, por tanto, de los principios del culteranismo (Canet Vallés, 1993: 111).

A este propósito conviene matizar, sin embargo que, a pesar de situarse en el contexto del campo literario al aludir, por ejemplo, a los «malos poetas» (1990: 375 , nota 27), Tárrega se refiere ante todo a la comunicación de todos los días, aplicando su crítica, por ejemplo, a los diálogos de monjas o al relato que un capitán general hace de una batalla a su mujer. Al ilustrar sus «castigos y consejos» lingüísticos mediante breves narraciones ejemplares, al estilo de los dichos, chistes y anécdotas analizados por Maxime Chevalier (1975, 1978 y 1999), Tárrega crea un texto híbrido y ameno, demostrando asimismo una aguda conciencia lingüística (Gauger, 1989) que remite a una retórica de la conversación situada entre oralidad y literalidad. Reprende hasta las omnipresentes muletillas o «bordonçillos», «a que muchos, sin propósito se arriman», como por ejemplo «"por esso digo", "como dixo el otro", "pensé que está v.m. en ello", "ahora bien"» (1990: 387) con el fin de proporcionar una norma segura para todo tipo de sociabilidad entre pública y privada, cortesana y ciudadana.

El «Discurso contra la demasiada cirimonia común» que «Sueño», i.e. Hernando Pretel, «poeta castellano» (Canet, Rodríguez y Sirera, 1988: 27), pronuncia en la 71. ${ }^{\circ}$ reunión de los Nocturnos (el 15 de diciembre de 1593) (Canet, Rodríguez y Sirera, 2000: 212-219), constituye por varios motivos una continuación de las observaciones precedentes sobre las necedades. También fustiga las necedades verbales y no verbales en el trato común, ilustrándolas igualmente con graciosas anécdotas. Al igual que Tárregas, Pretel tampoco sigue el esquema de las usuales disertaciones eruditas apoyadas en autoridades clásicas y bíblicas, sino que se basa en datos empíricos y breves relatos ejemplares por lo cual su ponencia es considerada como «uno de los Discursos más atípicos - y por ello más interesante- de los que se recogieron en las sesiones de la Academia», uniendo la «sátira costumbrista» con «apreciaciones» que recuerdan «los escritos de los arbitristas» (2000: 214-215, nota 11).

Con referencia a Don Quijote véase también los «regüeldos» (Canet, Rodríguez y Sirera, 1990: 386 , nota 64$)$. 
Lo que el académico «Sueño» critica de manera acerba es, en principio, el deseo de distinción llevado al extremo y manifestado en mil detalles de la vida cotidiana tanto por aristócratas, damas y miembros del clero. Conforme con este mecanismo sociológico analizado de manera paradigmática por Pierre Bourdieu (1979), «no se tiene por buen cortesano ni de buen gusto el que no inventa novedades y estremos» (2000: 213). En este sentido,

[...] quieren tratarse diferentemente de los que los demás de su estado usan, pensando que por ser altivos han de ser más estimados. Y ansí tienen hechas leyes y límites en los ademanes y trato, procurando que su tiple vaya de ordinario un punto más alto que los demás, siendo hecho arancel en el modo de hablar y saludar, hecharia en el estilo con que han de corresponder y diferenciar a los que con ellos tratan, y ciégales su vanidad a vezes [...] (2000: 213).

Frente la sociedad de su tiempo, en la que «cada cual quiere llevar su vanidad hasta el cabo», el académico opina, citando a Jorge Manrique, «que era mejor el tiempo pasado» (2000, 214, nota 9). A la «arrogancia» (2000: 216), «vanidad» y «ambición» (2000: 214) de sus coetáneos, les opone la «llaneza y modestia» (2000: 215) de los antiguos, representada de manera ejemplar por los Reyes Católicos, recordando «la benignidad con que confirieron y agasajaron sus súbditos, pues con más facilidad se hablaba entonces con ellos que agora con un criado de un s[eñ]or particular» (2000: 216). Es precisamente en las relaciones entre amo y criado donde se revela con más nitidez el afán de distinción que opera en todos los niveles de la escala social a través del fetichismo de los títulos:

Y esto no lo ha hecho otra cosa mas de ver querido cada qual entrarse y enseñorearse en la ceremonia y comedimiento más de aquello que le toca, corriéndose el criado si el s[eñ]or le llama 'vos' a secas, y el s[eñ]or si le llaman sola 'merced', queriéndose señoría el que no tiene título, y el que le tiene 'exellencia' (2000: 216).

El duque de Alba, «hombre por estremo altivo» (2000: 216), es mencionado como prototipo de esta soberbia, cuya «demasía» es castigada de manera ejemplar por el bon mot difundido por la anécdota de otro noble a propósito de acordarle o quitarle a alguien el título (2000: 216). Las mujeres de la nobleza son representadas en el discurso como particularmente «extremadas» (2000: 217) al sustituir la «franqueza» de antaño por los «melindres» (2000: 216), sea en el ámbito verbal, al usar «vocablos inusitados», sea en el no verbal y gestual, al afectar, por ejemplo, unas reverencias de zarabanda que el académico describe de manera tan plástica como satírica:

Otras ay que siguen diferente seta, haciendo las reverencias por mudanças de çarabanda: quál encoxe sola una pierna, que parece grillo sin ella; quál tuerce el 
cuerpo a un lado, guardando las junturas como elefantes, y otras porque no les caçen como a ellos, juegan de ombro y cuello. Y a fe, que no lo hacen porque no sepan a su tiempo brincallo (2000: 217).

Incluso más allá de los círculos cortesanos «es general esta lepra del vano comedimiento y uso común, tanto que hasta las aras sagradas le dan feudo» (2000: 218). El problema fundamental del fenómeno analizado por el académico estriba en la subversión de los criterios ideales establecidos por Castiglione en su Cortegiano, pues «buen gusto» cortesano y «común vulgo» se confunden (2000: 212-213) - una cuestión que se plantea tal vez de manera especial en una sociedad como la de Valencia, entre patricia-municipal y cortesana-. En consideración de la función sociocultural que cumple la Academia de los Nocturnos en el particular entorno valenciano al capacitar a los representantes de los estamentos superiores de la ciudad a un comportamiento a la vez correcto y desenvuelto, el ponente no solo recuerda a sus oyentes las normas tradicionales del verdadero «buen gusto», sino que les preserva de ponerse en ridículo.

Al erigir en señal distintiva determinadas extravagancias de la moda, que por su misma dinámica de lo nuevo llevan al absurdo, «desterrando una novedad con otra mayor» (2000: 219), los obcecados por la distinción desencadenan una dinámica que lleva a su propia negación, pues «las mismas invenciones del uso son quien le distrahe y anichila» (2000: 219). Con ello, los presumidos, «vienen a caher en cosas que son chacota ordinaria y hablilla del mundo, pareciéndoles que por solo eligirlos ellos es bueno» (2000: 213). De esta manera, los promotores de las novedades criticadas resultan «enfadosos y pesados» y se exponen al ridículo, «sirv[iendo] de mofa y fisga en las conversaciones» (2000: 213).

De manera que podemos decir con raçón que este género de gente son como máscara y entremés del mundo, pues andan en él como la tarabilla sobre la piedra del molino, dando a entender que son los moledores del buen gusto, celebrando oy lo que ayer vituperaron $[\ldots]$ (2000: 218).

Al final de su «Discurso contra la demasiada cirimonia común», Pretel anuncia una continuación: «ya que este discurso ha sido de la viciosa pulicía, prometo tratar en otro de la que es lícita y cortesana, dexando por agora, como dizen, "a cada loco con su tema", pues el querelles reducir a límites de raçón será predicar en desierto» (2000: 219). Sin embargo, esta segunda parte, destinada a formular de manera positiva las normas de la «pulicía [... lícita y cortesana» (2000: 213), nunca sería publicada, debido a que estas ya se conocen de sobra por encontrarse en cada uno de los numerosos tratados epígonos del Cortegiano (Burke, 1998).

A este respecto merece una breve digresión el Libro intitulado el Cortesano, publicado en 1561 en la misma ciudad de Valencia y dedicado por su 
autor, Luis Milán, al rey Felipe II de España. El punto de partida del tratado es la proyección ficcionalizada de un grupo de «ciertas damas de Valencia: que tenían entre manos el Cortesano del conde Balthasar Castillon: Dixeron que me parecía de él. Yo dije: Más querría servos conde, que no don Luis Milán: por estar en esas manos, donde yo querría estar» (Milán, 1561: s.p.). Correspondiendo al reto de las bellas y conforme al principio de la aemulatio, el autor pretende reflejar otro contexto cultural digno de la corte de Urbino, a saber la de los virreyes de Valencia, Fernando de Aragón (1488-1550) y Germana de Foix (1488-1536). El propósito de su obra, estructurada en seis jornadas, se centra en la retórica de la conversación cortesana, con sus burlas livianas, haciendo hincapié en el plurilingüismo y el rol particular de «nuestra lengua Valenciana»:

Da modo y avisos de hablar sin verbosidad ni afectación, ni cortedad de palabra, que sea para esconder la razón. Dando conversaciones para saber burlar a modo de palacio. Representa la corte del Real Duque de Calabria y la Reyna Germana: con todas aquellas damas y caballeros de aquel tiempo. [...] Haciendo que hablen en uestra lengua Valenciana como ellos hablaban. Pues muchos que han escrito usaron escribir en diversas lenguas: Para bien representar el natural de cada uno (Milán, 1561: s.p.).

Esta variedad de idiomas (nacionales) y estilos (retóricos y sociales) también se destaca en la parte conclusiva de la obra:

La intención mía en este Cortesano ha sido representar todo lo que en Corte de Príncipes se trata: Diversidad de lenguas, por las diversas naciones que suele tener. Uso de todo los estilos, usando el Altiloco en las cosas altas, que son consejos y pareceres para gobernar nuestra vida y estados. Sirviéndome del Mediocre, para las conversaciones jocosas de graves Cortesanos. Exercitando el Infimo para las pláticas risueñas de Donosos y Truhanes, que [...] alivian de las pesadumbres de los negocios y gravedades (Milán, 1561: s.p.).

Una generación posterior al tratado de 1561 , los discursos analizados de los académicos valencianos desplazan el foco de interés desde el palacio y la corte hacia el espacio urbano, en concreto a la academia, como institución que reúne nobles y burgueses, clérigos y letrados, poetas aficionados y profesionales. A pesar de estos cambios socioculturales y de la variedad de hablas y estilos, el ideal de la claridad, así como el sentido de la burla dentro de los límites del decoro siguen vigentes como normas de sociabilidad entre el Cortesano valenciano y los discursos académicos de finales del siglo XVI.

Para concluir, podemos afirmar que los discursos dedicados a determinados aspectos de la sociabilidad forman parte del «[a]prendizaje literario» 
proporcionado por la Academia valenciana, «imprescindible en una sociedad cuya clase dirigente, la nobleza, en su intento de imitar al perfecto cortesano, lo incluye como elemento integrante del ocio y de las fiestas, posibilitándole además alcanzar fama y renombre» (Canet Vallés, 1993: 124). De manera significativa, ambos discursos sobre las necedades de la conversación y los excesos de la civilidad se distinguen del esquema retórico respetado habitualmente en los discursos académicos, al abandonar las referencias humanísticas y bíblicas a favor de la observación empírica, salpicada de graciosas anécdotas que sirven de ejemplo y reflejan, asimismo, situaciones reales de sociabilidad y conversación. Con ello, estos dos discursos llegan a conformar un género híbrido, entre escrito y oral, expositivo y narrativo. Asimismo, al proporcionar determinadas normas de conducta para la vida en sociedad, los discursos analizados corresponden de manera paradigmática a la finalidad de la Academia de los Nocturnos, que consiste en «conseguir las bases para desenvolverse con soltura en una sociedad cada vez más elitista, que hace del fasto y la fiesta casi el único motivo de su existencia» (Canet Vallés, 1993: 124). Mediante su reflexión sobre las reglas de la sociabilidad desde la misma sociabilidad institucionalizada de las academias, los discursos aquí analizados contribuyen también a formar al joven literato áureo y a integrarlo en redes entre cortesanas y urbanas, beneficiosas para su consagración social.

BiBLIOGRAFÍA

AlBerT, Mechthild (2012). «El discurso de la comida en la novela corta del Siglo de Oro». En María Luisa Cerrón Puga (ed.), Rumbos del hispanismo en el umbral del Cincuentenario de la AIH. Roma: Bagatto Libri, t. III, pp. 348-354.

AlBerT, Mechthild (2013a). «Topologías de la sociabilidad en la novela corta del Siglo de Oro». En Eberhard Geisler (ed.), La representación del espacio en la literatura española del Siglo de Oro. Barcelona: Anthropos, pp. 313-334.

Albert, Mechthild (2013b). «Sociabilidad: el término y el fenómeno». En Mechthild Albert (ed.), Sociabilidad y literatura en el Siglo de Oro. Madrid / Frankfurt am Main: Vervuert / Iberoamericana, pp. 7-18.

AlBerT, Mechthild (2018). «La sociabilidad: un concepto clave de los estudios culturales y literarios en el ámbito hispánico». En Christoph Strosetzki (ed.), Aspectos mundiales del hispanismo actual. Literatura-Cultura-Lengua. Berlin / Boston: De Gruyter, t. I, pp. 9-25.

Bourdieu, Pierre (1979). La distinction. Critique sociale du jugement. Paris: Les Éditions de Minuit.

Bourdieu, Pierre (1992). Les règles de l'art: genèse et structure du champ littéraire. Paris: Seuil.

Burke, Peter (1998). Los avatares de «El cortesano». Lecturas y lectores de un texto clave del espiritu renacentista. Barcelona: Gedisa. 
CANET Vallés, José Luis (1993). «Estructura del saber y estructura del poder: organización y funciones de la Academia de los Nocturnos de Valencia». En Evangelina Rodríguez (ed.), De las Academias a la Enciclopedia: El discurso del saber en la modernidad. València: Alfons el Magnànim, pp. 95-124.

CAnet, José Luis, Evangelina Rodríguez y José Luis Sirera (eds.) (1988-2000). Actas de la Academia de los Nocturnos. València: Alfons el Magnànim.

Chevalier, Maxime (1975). Cuentecillos tradicionales en la España del Siglo de Oro. Madrid: Gredos.

Chevalier, Maxime (1978). Folclore y literatura: el cuento oral en el Siglo de Oro. Barcelona: Crítica.

Chevalier, Maxime (1999). Cuento tradicional, cultura, literatura (siglos XVI-XIX). Salamanca: Universidad de Salamanca.

CRuz, Anne J. (1995). «Art of the State: The Academias literarias as Sites of Symbolic Economies in Golden Age Spain». Caliope, 1.1-2, pp. 72-95.

Cruz, Anne J. (1998). «Las academias: literatura y poder en un espacio cortesano». Edad de Oro, 17 , pp. 49-57.

García García, Bernardo (coord.) (2007). Dramaturgia festiva y cultura nobiliaria en el Siglo de Oro. Madrid / Frankurt am Main: Iberoamericana / Vervuert.

Gauger, Hans-Martin (1989). «La Conciencia Lingüística En El Siglo De Oro». En Walther L. Bernecker et alii., Actas del IX Congreso de la Asociación Internacional de Hispanistas. Frankfurt am Main: Vervuert, pp. 45-63.

Gutiérrez, Carlos Manuel (2005). La espada, el rayo y la pluma. Quevedo y los campos literario y de poder. West Lafayette: Purdue University Press.

JANIK, Dieter (2013). «La sociabilidad de la Academia de los Nocturnos: Modalidades expositivas y comunicativas de los discursos leídos». En Mechthild Albert (ed.), Sociabilidad y literatura en el Siglo de Oro. Madrid / Frankfurt am Main: Iberoamericana / Vervuert, pp. 165-177.

KING, Willard F. (1963). Prosa novelística y academias literarias en el siglo XVII. Madrid: Boletín de la Real Academia Española.

LobAto, María Luisa y Bernardo J. GARCía GARCía (coords.) (2003). La fiesta cortesana en la época de los Austrias. Valladolid: Junta de Castilla y León.

Mas I Usó, Pasqual (1996). Academias y justas literarias en la Valencia barroca. Teoría y práctica de una convención. Kassel: Edition Reichenberger.

Milán, Luis (1561). Libro intitulado el Cortesano dirigido a don Phelipe. València: Joan de Arcos <http://bdh-rd.bne.es/viewer.vm?id=0000170830\&page=1> [Consulta: 10/04/2019].

Prieto de Paula, Ángel Luis (1995). «El modelo italiano en la formación de las academias literarias españolas del primer barroco: Los "Nocturnos" como paradigma». En Enrique Giménez, Juan A. Ríos Carratalá y Enrique Rubio Cremades (eds.), Relaciones culturales entre Italia y España: III Encuentro entre las universidades de Macerata y Alicante (marzo, 1994). Alicante: Universidad de Alicante, pp. 133-148.

Rodríguez CuAdros, Evangelina (1993). «Del saber cenacular a la Ilustración: el borrador enciclopédico de la Academia de los Nocturnos». En Evangelina Rodríguez (ed.), De

Edad de Oro, XXXIX (2020), pp. 145-157, ISSN: 0212-0429 - ISSNe: 2605-3314 
las Academias a la Enciclopedia: El discurso del saber en la modernidad. València: Alfons el Magnànim, pp. 27-67.

RodríGUEZ SÁNCHEZ DE LEÓN, José (1989). «La academia literaria como fiesta barroca en tres ejemplos andaluces: (1661, 1664 y 1672)». Diálogos Hispánicos de Amsterdam, 8.3, pp. 915-926.

ROMERo-DíAz, Nieves (2002). Nueva nobleza, nueva novela: reescribiendo la cultura urbana del barroco. Newark: Juan de la Cuesta.

SÁnchez, José (1961). Academias literarias del Siglo de Oro Español. Madrid: Gredos.

Strosetzki, Christoph (1997). La literatura como profesión: En torno a la autoconcepción de la existencia erudita y literaria en el Siglo de Oro español. Kassel: Edition Reichenberger.

VIALA, Alain (1985). Naissance de l'écrivain: Sociologie de la littérature à l'âge classique. Paris: Les Editions de Minuit.

Recibido: $16 / 04 / 2019$

Aceptado: 21/12/2019 


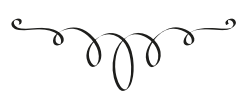

LA SOCIABILIDAD REFLEJADA A TRAVÉS DE LOS DISCURSOS de la Academia de los Nocturnos (Valencia, 1591-1594)

RESUMEN: A través de tres discursos pronunciados en el marco de la Academia de los Nocturnos (Valencia, 1591-1594) y dedicados a aspectos socioculturales, retóricos y lingüísticos, el presente artículo pretende analizar la sociabilidad entre cortesana y urbana que caracterizaba esta institución crucial del campo literario áureo.

Palabras Clave: Academias, sociabilidad, campo literario, Academia de los Nocturnos, discursos académicos.

THE SOCIABILITY REFLECTED THROUGH THE LECTURES of the Academia de los Nocturnos (Valencia, 1591-1594)

ABSTRACT: Based on three lectures delivered in the Academia de los Nocturnos (Valencia, 1591-1594), dedicated to socio-cultural, rhetorical and linguistic aspects, this article aims to analyze the sociability between the courtly and the urban that characterized this crucial institution of the literary field in the Spanish Golden Age.

Keywords: Academies, Sociability, Literary Field, Academia de los Nocturnos, Academic Discourses. 